\title{
PENURUNAN BEBAN DAN PENINGKATAN KEMAMPUAN MERAWAT KELUARGA DENGAN KLIEN HALUSINASI MELALUI FAMILY PSYCHOEDUCATION
}

\author{
Shanti Wardaningsih*, Budi Anna Keliat**, Herni Susanti**
}

\begin{abstract}
Abstrak
Penelitian ini bertujuan untuk mengetahui pengaruh Family Psychoeducation terhadap beban dan kemampuan keluarga dalam merawat klien dengan halusinasi. Penelitian menggunakan metode kuantitatif dengan pendekatan kuasi eksperimen. Tempat penelitian dilakukan di 4 Puskesmas di Kabupaten Bantul yaitu Puskesmas Kasihan 1, Kasihan 2, Sewon 1 dan Imogiri 1. Pengambilan sampel menggunakan simple random sampling dengan sampel sebanyak 28 untuk masing-masing kelompok kontrol dan intervensi. Data dikumpulkan dengan kuesioner dan modul intervensi yaitu Family Psychoeducation. Hasil penelitian ini menunjukkan adanya pengaruh Family Psychoeducation yaitu penurunan beban dan peningkatan kemampuan keluarga dalam merawat klien dengan halusinasi. Rekomendasi penelitian ini terutama ditujukan kepada pelayanan kesehatan di puskesmas agar menfasilitasi untuk penerapan family psychoeducation bagi keluarga yang memiliki anggota keluarga yang mengalami gangguan jiwa.
\end{abstract}

Kata kunci: beban keluarga, kemampuan keluarga, family psychoeducation

\begin{abstract}
This research aimed to find out the effect of family psychoeducation toward the family burden and ability in taking care of the patient with hallucination. The research was used the quantitative method and quasi experiment approach. This study was carried out in 4 puskesmas in Kabupaten Bantul, which were puskesmas Kasihan 1, Kasihan 2, Sewon 1, and Imogiri 1. The sampling method used the simple random sampling with the total sample of 28 for each control and intervention group. The data was then collected using questionnaire and intervention module which was family psychoeducation. The result of research showed that there was the effect of family psychoeducation, shown by the decrease in family burden and the increase in the family ability in taking care of the patient with hallucination. This study recommended, especially for the health service in puskesmas, to facilitate the implementation of family psychoeducation to the family whose family member was suffered from mental disturbance.
\end{abstract}

Keyword: family burden, family ability, family psychoeducation

\section{PENDAHULUAN}

Gangguan jiwa adalah penyakit yang menyebabkan gangguan pada proses pikir dan atau tingkah laku yang mengakibatkan ketidakmampuan seseorang untuk mengambil keputusaan dalam kehidupan sehari-harinya (National Mental Health Association, 2000).

Konsep gangguan jiwa dari Diagnostic and Statistical Manual of Mental Disorders (DSMIV-TR) $4^{\text {th }}$ edition (1994) adalah "gangguan jiwa didefinisikan sebagai kumpulan gejala (sindrom) atau pola klinik yang signifikan dari perilaku dan psikologis yang terjadi pada individu dan dikaitkan dengan stress dan ketidakmampuan (kerusakan fungsi dalam satu area atau lebih) atau meningkatan resiko penderitaan, ketidakmampuan atau kehilangan kebebasan". Menurut Survei Kesehatan Rumah Tangga (SKRT) 1995, di Indonesia diperkirakan sebesar 186 dari 1000 anggota rumah tangga menderita gangguan jiwa. Gangguan berat yang sering terjadi adalah depresi, bipolar disorder, demensia, skizofrenia dan anxiety disorders.

Skizofrenia adalah gangguan pada otak dan pola pikir (Torrey, 1997 dalam Carson, 2003). Skizofrenia mempunyai karakteristik dengan gejala positif dan negatif. Gejala positif antara lain thought echo, delusi, halusinasi. Halusinasi merupakan gejala positif yang paling sering muncul pada klien Skizofrenia. Menurut Thomas (1991), halusinasi secara umum dapat ditemukan pada pasien gangguan jiwa seperti skizoprenia, depresi, delirium dan kondisi yang berhubungan dengan penggunaan alkohol dan substansi lingkungan. 
Halusinasi merupakan distorsi persepsi yang salah, yang terjadi karena respon neurobiologi. Pasien mempunyai pengalaman aktual terhadap distorsi sensori terhadap apa yang sebenarnya terjadi (Stuart \& Laraia, 2005). Pada pasien psikiatrik semua dari lima indera dapat dipengaruhi oleh pengalaman halusinasi (Kaplan, 1996).

Halusinasi yang paling sering adalah halusinasi dengar, kurang lebih sekitar $70 \%$ (Stuart \& Laraia, 2005). Suara - suara tersebut seringkali mengancam, kotor, menuduh, atau menghina. Dua atau lebih suara dapat saling berbicara satu sama lainnya, atau sebuah suara mungkin berkomentar tentang perilaku atau kehidupan klien (Kaplan, 1996).

Gangguan jiwa dalam kurun waktu singkat apalagi jangka panjang, akan mengakibatkan beban pada klien, keluarga serta negara. Di seluruh dunia, sedikitnya $25 \%$ klien dan keluarganya terpengaruh dengan gangguan jiwa yang dialaminya sehingga mengakibatkan stress berat dan beban bagi mereka. Hal ini membuktikan bahwa gangguan jiwa sangat mempengaruhi kualitas hidup dari keluarga. (Walton-Moss, Gerson, \& Rose, 2005).

Setiawan (2006) mengatakan gangguan kesehatan jiwa relatif terabaikan, padahal penurunan produktivitas akibat gangguan kesehatan jiwa terbukti berdampak nyata pada perekonomian. Hasil studi Bank Dunia tahun 1995 di beberapa negara menunjukkan 8,1 persen hari-hari produktif hilang atau Disability Adjusted Life Years (DALY's) akibat beban penyakit yang disebabkan oleh masalah kesehatan jiwa. (Anonim, 2006).

Berdasarkan pernyataan Setiawan (2006) angka tersebut lebih besar dibandingkan hari-hari produktif yang hilang akibat penyakit tuberkulosis $(7,2 \%)$, kanker $(5,8 \%)$, penyakit jantung $(4,4 \%)$, dan malaria $(2,6 \%)$. Kerugian ekonomi akibat penyakit gangguan jiwa di Indonesia mencapai Rp 32 triliun per tahun. Jumlah penderita penyakit ini cukup tinggi dan cenderung meningkat daritahun ke tahun (Anonim, 2006).

Upaya dalam mengatasi masalah yang diakibatkan gangguan jiwa dilakukan dengan upaya pencegahan primer, sekunder dan tersier secara menyeluruh dilakukan untuk dapat mengurangi beban bagi keluarga dan bagi klien. Berdasarkan catatan dari Schyzophrenia Patient Outcomes Research
Team (PORT), kegagalan dari terapi individu yang dilakukan kepada klien skizofrenia diakibatkan karena hanya $10 \%$ keluarga yang mendapatkan pendidikan kesehatan (Lehman \& Steinwachs, 1998 dalam Mohr, 2006). Berdasarkan hal tersebut, maka terapi terhadap individu klien akan lebih mendapatkan hasil yang lebih baik apabila disertai terapi sekeluarga.

National Aliance for Mentally Ill (NAMI) dan beberapa organisasi lain mendesain program Family Psychoeducation untuk memberikan dukungan kepada keluarga. Program ini sangat bervariasi, namun demikian tujuannya sama yaitu memberikan informasi dan pendidikan kepada keluarga (Stuart \& Laraia, 2005).

Family psychoeducation dapat mengurangi stress, kebingungan, dan kecemasan pada keluarga klien gangguan jiwa, yang diharapkan dapat membantu keluarga mereka yang gangguan jiwa (Psycho-Educational Counseling Services, 2000).

Murray dan Dixon (2003) mensintesakan beberapa penelitian tentang psychoeducation yang akhirnya menjadi Evidance Based Practice dalam kesehatan jiwa. Kesimpulan mereka bahwa Family Psychoeducation adalah evidance based practice yang tingkat keefektifannya tinggi, terutama untuk mengurangi kekambuhan klien dengan skizofrenia dan gangguan skizoakfektif.

Hasilnya mengindikasikan bahwa klien yang mendapatkan terapi individu dan medis serta keluarga mereka yang mendapatkan intervensi ini kemungkinan kekambuhannya $15 \%$, sedangkan yang hanya mendapatkan terapi medis dan individu saja kemungkinan kambuh 30-40 \%. Disimpulkan juga bahwa Family Psychoeducation dapat meningkatkan kesejahteraan keluarga serta menurunkan beban subjektif keluarga.

Kabupaten Bantul pada tahun 2004 mempunyai jumlah penduduk 816.256 jiwa tersebar dalam 17 kecamatan. Fasilitas kesehatan yang ada di wilayah kabupaten Bantul terdiri dari 3 rumah sakit umum dan 105 puskesmas. Bencana gempa bumi yang terjadi di wilayah pada tanggal 27 Mei 2006 lalu menjadikan Bantul sebagai wilayah terparah yang mendapatkan dampaknya. Dengan keadaan tersebut, sangat mungkin jumlah klien gangguan jiwa meningkat. 
Pada saat yang sama, peneliti mengobservasi jumlah klien yang dirawat di Rumah Sakit Grhasia mengalami peningkatan hingga $75 \%$ dari Bed of Rate rumah sakit.

Berdasarkan data yang didapatkan dari Dinas Kesehatan Kabupaten Bantul, tercatat sekitar 2.360 orang, dan sebagian besar adalah klien skizofrenia yang mengalami halusinasi. Di salah satu Puskesmas yaitu Puskesmas Imogiri I, perawat kesehatan jiwa mengatakan bahwa klien sering tidak melakukan kontrol rutin karena kendala biaya dan merasa telah sembuh.

\section{METODE}

Penelitian ini menggunakan rancangan penelitian studi komparatif eksperimen semu (quasi experiment), dengan pendekatan pre-post test design yaitu pengukuran dilakukan pada awal dan saat akhir penelitian (Arikunto, 1998). Melalui desain ini dimaksudkan untuk mencari hubungan sebab akibat dengan adanya keterlibatan penelitian dalam melakukan manipulasi terhadap variabel bebas (Polit \& Hungler, 1999; Burn \& Grove, 1991).

Pengukuran ini dilakukan sebelum dan sesudah intervensi Family Psychoeducation pada kelompok intervensi dan dilakukanjuga pada kelompok kontrol yang tidak diberikan Family Psychoeducation. Beban keluarga dan kemampuan keluarga merawat klien halusinasi sebelum Family Psychoeducation dibandingkan dengan setelah intervensi.

Sampel dalam penelitian ini diambil secara simple random sampling, yaitu pengambilan sampel secara acak sederhana. Hakikat dari pengambilan sampel secara acak adalah bahwa setiap anggota atau unit dari populasi mempunyai kesempatan yang sama untuk diseleksi sebagai sampel (Notoatmodjo, 2005).

Sampel diambil daripopulasi individu perwakilan keluarga klien dengan halusinasi yang memenuhi kriteria inklusi sebagai berikut: 1) bersedia menjadi responden pada penelitian, 2) keluarga yang mempunyai anggota keluarga dengan halusinasi, 3) mempunyai hubungan dekat dengan klien, misalnya anak, pasangan (istri atau suami), orang tua, 4) usia dewasa (18 tahun keatas), 5) bertanggung jawab terhadap klien dan tinggal bersama klien, 5) sehat jiwa.
Pada penelitian ini jumlah sampel sebanyak 28 orang untuk masing-masing kelompok kontrol dan intervensi, dengan merujuk rumus jumlah sampel uji hipotesis beda rata-rata berpasangan (dependent). Penelitian ini dilakukan di 4 Puskesmas Wilayah Kabupaten Bantul yaitu Puskesmas Kasihan 1, Kasihan 2, Imogiri 1 dan Sewon 1, dengan alasan bahwa wilayah ini merupakan wilayah yang barusaja mengalami bencana gempa bumi, sehingga angka gangguan jiwa yang ditemukan tinggi.

Instrumen atau alat pengumpul data yang dipergunakan dalam penelitian ini berupa pedoman wawancara dengan metode wawancara terstruktur, sebagai berikut: Instrumen untuk data diri responden dan klien, terdiri dari usia, pendidikan, suku, agama, pekerjaan, alamat, penghasilan, lama keluarga menderita gangguan jiwa, hubungan dengan klien. Data diperoleh dengan wawancara data mengenai karakteristik klien meliputi; usia klien, jenis kelamin, peran klien dalam keluarga, pertama kali klien menderita gangguan jiwa (onset). Instrumen untuk variabel dependen: Beban subyektif dan obyektif keluarga instrumen untuk memperoleh data mengenai tingkat beban subyektif dan obyektif keluarga dengan menggunakan Caregiver Strain Index, jumlah pertanyaan terdiri dari 30 pertanyaan Instrumen untuk variabel dependen: kemampuan psikomotor dan kognitif keluarga dalam merawat klien halusinasi terdiri dari 14 pertanyaan.

Pre test dilakukan dengan mengukur beban dan kemampuan keluarga pada kelompok intervensi dan kelompok kontrol, kemudian data diedit dan diolah sesuai dengan rencana analisis data. Setelah dilakukan pretest, kemudian dilakukan uji kesetaraan antara kelompok kontrol dan intervensi. Hasil pretest dari kelompok intervensi dan kelompok kontrol nantinya akan dibandingkan dengan hasil postest dari masing-masing kelompok intervensi dan kontrol. Kelompok intervensi dilakukan Family Psychoeducation yang merupakan terapi kelompok yang berorientasi terhadap individu.

Kelompok intervensi dan kontrol, setelah diberikan Family Psychoeducation akan dilakukan post test pada akhir intervensi untuk mengukur beban dan kemampuan keluarga klien dengan halusinasi. Kemudian dibandingkan kembali beban dan kemampuan keluarga antara kelompok intervensi dan kontrol tersebut. 


\section{HASIL}

Hasil analisis bivariat dari penelitian ini adalah:

1. Beban pada kelompok kontrol dan kelompok intervensi sebelum dan sesudah intervensi menunjukkan kemaknaan $(p=0,000, \alpha=0,05)$. Hasil analisis juga memperlihatkan perbedaan beban keluarga pada kelompok intervensi setelah dilakukan family psychoeducation mengalami penurunan yang bermakna yaitu 6,82 .

Tabel. 1

Analisis Perbedaan Beban Keluarga Kelompok Intervensi dan Kontrol Sebelum dan Sesudah dilakukan Family Psychoeducation Di Kabupaten Bantul, 2007

\begin{tabular}{ccccccc}
\hline Kelompok & Variabel & n & Mean & SD & t & p \\
\hline Intervensi & Beban & & & & & \\
& 1. Sebelum & 28 & 60,04 & 11,27 & 11,012 & 0,000 \\
& 2. Sesudah & 28 & 53,21 & 10,699 & & \\
& $\begin{array}{c}\text { Perbedaan rata-rata } \\
\text { beban }\end{array}$ & $-6,82$ & 3,278 & & \\
Kontrol & $\begin{array}{lllll}\text { Beban } \\
\end{array}$ & & & & \\
& 1. Sebelum & 28 & 57,57 & 11,987 & 1,078 & 0,290 \\
& 2. Sesudah & 28 & 58,29 & 12,261 & & \\
& $\begin{array}{c}\text { Perbedaan rata-rata } \\
\text { beban }\end{array}$ & 0,71 & 3,5 & & \\
\hline
\end{tabular}

Tabel. 2

Analisis Perbedaan Kemampuan Keluarga Kelompok Kontrol dan Intervensi Sebelum dan Sesudah dilakukan Family Psychoeducation Di Kabupaten Bantul, 2007

\begin{tabular}{|c|c|c|c|c|c|c|}
\hline Kelompok & Variabel & $\mathbf{n}$ & Mean & SD & $\mathbf{t}$ & p \\
\hline \multirow{4}{*}{ Intervensi } & Kemampuan & & & & \multirow{4}{*}{$-19,9$} & \multirow{4}{*}{0,00} \\
\hline & 1.Sebelum & 28 & 57,96 & 9,118 & & \\
\hline & 2.Sesudah & 28 & 83,32 & 6,510 & & \\
\hline & $\begin{array}{l}\text { Perbedaan Rata } \\
\text { Kemampua }\end{array}$ & & 25,36 & 6,740 & & \\
\hline \multirow[t]{4}{*}{ Kontrol } & Kemampuan & & & & \multirow{4}{*}{0,872} & \multirow{4}{*}{0,391} \\
\hline & 1. Sebelum & 28 & 68,89 & 10,993 & & \\
\hline & 2. Sesud ah & 28 & 68,00 & 10,789 & & \\
\hline & \multicolumn{2}{|c|}{$\begin{array}{l}\text { Perbedaan rata-rata } \\
\text { Kemampuan }\end{array}$} & 0,89 & 5,416 & & \\
\hline
\end{tabular}

2. Kemampuan pada kelompok kontrol dan kelompok intervensi sebelum dan sesudah intervensi menunjukkan perbedaan ( $\mathrm{p}=0,000$, $\alpha=0,05)$. Hasil analisis juga memperlihatkan perbedaan kemampuan keluarga pada kelompok intervensi setelah dilakukan family psychoeducation mengalami peningkatan yang bermakna yaitu 25,36 .

3. Karakteristik keluarga tidak mempunyai hubungan yang bermakna terhadap beban dan kemampuan keluarga dalam merawat klien dengan halusinasi $(p>0,05, \alpha=0,05)$.

4. Karakteristik klien yaitu rutinitas berobat mempunyai hubungan yang bermakna terhadap beban dan kemampuan keluarga $(p=0,016, \alpha=$ $0,05)$.

\section{PEMBAHASAN}

Family psychoeducation dapat menurunkan beban keluarga dalam merawat klien dengan halusinasi. Hal ini sesuai dengan pendapat Hal ini sesuai dengan Murray dan Dixon (2003) yang mensintesiskan beberapa penelitian tentang psychoeducation yang akhirnya menjadi Evidence Based Practice dalam kesehatan jiwa. Murray dan Dixon selanjutnya menyimpulkan bahwa Family Psychoeducation adalah evidence based practice yang tingkat keefektifannya tinggi, terutama untuk mengurangi kekambuhan klien dengan skizofrenia dan gangguan skizoakfektif.

Hasil penelitian mengindikasikan bahwa klien yang mendapatkan terapi individu dan medis serta keluarga mereka yang mendapatkan family psychoeducation ini kemungkinan kekambuhannya adalah $15 \%$, sedangkan yang hanya mendapatkan terapi medis dan individu saja kemungkinan kambuh 30-40\%. Disimpulkan juga bahwa Family Psychoeducation dapat meningkatkan kesejahteraan keluarga serta menurunkan beban subyektif keluarga.

Hasil penelitian ini sesuai teori yang disampaikan oleh Goldenberg dan Goldengberg (2004) bahwa Family Psychoeducation adalah terapi yang digunakan untuk memberikan informasi terhadap keluarga yang mengalami distress, memberikan pendidikan pada mereka untuk meningkatkan ketrampilan untuk dapat memahami dan mempunyai koping akibat gangguan jiwa yang mengakibatkan masalah pada hubungan keluarganya

\section{KESIMPULAN}

Berdasarkan penelitian yang dilakukan dapat disimpulkan Family Psychoeducation menurunkan beban keluarga dan meningkatkan kemampuan merawat klien dengan halusinasi di Bantul. 
Karakteristik keluarga (usia, hubungan dengan klien, agama, pendidikan, pekerjaan, penghasilan), bukan merupakan variabel konfonding terhadap beban dan kemampuan keluarga setelah dilakukan Family Psychoeducation Kabupaten Bantul Yogyakarta.

Karakteristik klien (usia, jenis kelamin, lama sakit, jumlah kekambuhan, jumlah dirawat di RS) tidak berhubungan dengan beban dan kemampuan keluarga setelah dilakukan Family Psychoeducation Kabupaten Bantul Yogyakarta. Karakteristik klien yaitu rutinitas berobat berhubungan dengan beban keluarga pada saat dilakukan Family Psychoeducation (DN, BK, HR).

* Staf Akademik Keperawatan Jiwa Universitas Muhammadiyah Yogyakarta, Yogyakarta

**Staf Akademik Kelompok Keilmuan Keperawatan Jiwa FIK UI, Depok

\section{KEPUSTAKAAN}

Friedman, M.M. (1998). Keperawatan keluarga: Teori dan praktik. Jakarta: EGC.

Goldenberg, I., \& Goldenberg, H. (2004). Family therapy an overview. Sixth edition. United States: Thomson.

National Mental Health Association. (2000). Mental Illness in family recognized the warning sign and how to cope. Diperoleh dari www.nha.org.

Notoatmodjo, S. (2003). Pendidikan dan perilaku kesehatan. Jakarta: Rineka Cipta.

Polit, D. F., \& Hungler, B.P. (1997). Essensial of nursing research: Methods, apprasials and utilization (4th edition). Philadelphia: Lippincott.

Psycho-Educational Counseling Services. (2003). Psychoeducation.Diperoleh dari http:// www.psychoeducation.com.

Stuart, G.W \& Laraia (2005). Principles and pratice of psychiatric nursing (8th edition). Philadelphia: Elsevier Mosby.

Jenius adalah $1 \%$ inspirasi dan $99 \%$ keringat.

Tidak ada yang dapat menggantikan kerja keras.

Keberuntungan adalah sesuatu yang terjadi ketika kesempatan bertemu dengan kesiapan.

- Thomas A. Edison-

Bersikaplah kukuh seperti batu karang yang tidak putus-putus-nya dipukul ombak.

Ia tidak saja tetap berdiri kukuh, bahkan ia menenteramkan amarah ombak dan gelombang itu.

- Marcus Aurelius -

Suatu kehidupan yang penuh kesalahan tak hanya lebih berharga namun juga lebih berguna dibandingkan hidup tanpa melakukan apapun.

- George Bernard Shaw -

Pengetahuan ada dua macam: yang telah kita ketahui dengan sendirinya atau yang hanya kita ketahui dimana ia bisa didapatkan.

- Samuel Johnson - 